likely to listen to only when they hear them from outside.

But why should there be six research councils to administer such a relatively small budget? Apart from the four listed above, there are the newly created Danish National Research Foundation and a research council for the social sciences. The simple answer is that Denmark likes it that way. The system is designed to allow for endless consultation, which is what the Danish parliament does anyway. Moreover, with six councils in such a small country, the chances are very high that the members of particular research councils will know personally those who are applying for research support, with the advantage that referees' reports can be supplemented by personal knowledge. And of course it is always helpful to have more than just one chief source of funds.

Even so, Denmark is lucky to have avoided the difficulties that arise when, in a small community, grant-making consists of spreading what is available uniformly. The trick seems to have been not to be afraid of speaking out. That is helped in two ways - by the fact that every Danish academic can look to his university for basic research support and because most Danes seem uncommonly good-humoured.

\title{
New name for an old friend
}

One of Copenhagen's monuments that will survive is the facade of the Niels Bohr Institute, now almost hidden and certainly dwarfed by newer buildings of the University of Copenhagen as a whole. But the institute will, from next year, change its name and will become the Niels Bohr Institute of Physics, Astrophysics and Geophysics. Reverence for Bohr apart, the institute has been forced to recognize, during several lean years when academic vacancies could not be filled, that safety for the future rests on the construction of a larger academic unit, able to make a more obvious claim that it is active in both teaching and research. As a part of the deal, the government has apparently promised that it will never again be asked to leave academic posts vacant.

In reality, the Niels Bohr Institute remains as much a mecca for graduate students and postdoctoral fellows from abroad as it has ever



The Niels Bohr Institute - still as much a mecca as it always has been

\section{A council too many?}

WHAT does a government do with the proceeds of selling (or privatizing, as the British say) nationally owned assets? Sometimes the money simply disappears into the national treasury. In Denmark, the sale last year of a group of publicly owned insurance companies has led to the formation of an entirely new research council, the Danish National Research Foundation, with a capital of DKr2 billion. It will be Denmark's sixth and perhaps most controversial.

But why should anybody object to another pot of money for supporting research? There are several answers. One is that the existing research councils are not that well supplied with funds, even as things are. Another is that the terms of reference of the new council require it to make grants not to individual researchers but to groups of them or even, sometimes, to institutions: it is a fair question whether research projects of that kind deserve an estimated DKr150 million a year. And some complain that the new council will support research across the whole spectrum of scholarship, humanities as well as science and technology.

Professor Peder Olsen Larsen, the Aarhus physicist who is the first director of the new foundation, believes that the academic community will be persuaded when the first year's allocations of grants are made. So far, 350 research proposals have been screened by expert committees and individual referees. Applications on a short-list of $\mathbf{5 0}$ are now being discussed in detail with the applicants, who may have to make precise

been. Part of the explanation for that is that it lives cheek by jowl with the Nordic research enterprise NORDITA, which accommodates a necessarily more transient group of scientists with interests in previously vague budget estimates and will eventually be sent more formally for review (as often outside Denmark as within it). The first awards may be announced in the spring.

Some lucky survivors to the short-list say that the new council may be backing away from its first suggestion that grantholders should not simultaneously be members of a university or some other institution. The potential benefit of the new council is the flexibility it will have in apportioning funds between salaries, equipment and running costs and the chance that some of the grants it makes may be several millions of kroner.

Academics say that the value of these schemes is that they may allow people quickly to establish substantial groups of researchers in important fields. In recent years, the targeted biotechnology programme, which enabled a number of universities (Aarhus is one) to establish important research centres, has shown the potential value of large grants spread over several years.

But the new research council is meant to cover the whole of scholarship and is required by its enabling legislation to regard the erosion of its DKr2 billion endowment by inflation as a first charge on its annual income. The result of that may be that, with the continuing uncertainty about the interrelationship of European currencies, the research council may have little to spend in some years. It may be just as well that the council has let its first year go by without spending anything substantial on research.

ships but who are otherwise indistinguishable. NORDITA has itself been looked at carefully in the past few years, as part of the Nordic countries' repeated external evaluation of their institutions.

On the basis of what the external critics say, it seems likely that NORDITA will itself shift to a more distinctive pattern of research with particular topics being chosen in advance to be the subject of the institute's research for periods of three or six months at a time. But the same international evaluation of NORDITA took the view that it would not be proper to go so far as the Institute of Theoretical Physics at Santa Barbara, California, where there are funds sufficient to ensure that the institute's manageparticle physics, nuclear physics and astrophysics, who are on short-term fellow- ment can concentrate resources on the fields that it has chosen. 